\title{
The Importance of Professional Development Opportunities for Adjunct Instructors
}

Sarah Glancy*, Kirsten St. John, Megan Jones, and Thomas Gill

*University of Hawai'i -West O'ahu 


\section{University of Hawai'i - West O'ahu}

- $88 \%$ non-Caucasian

- Over 27\% Hawaiian/Pacific Islander

- Many non-traditional students (median age is 27)

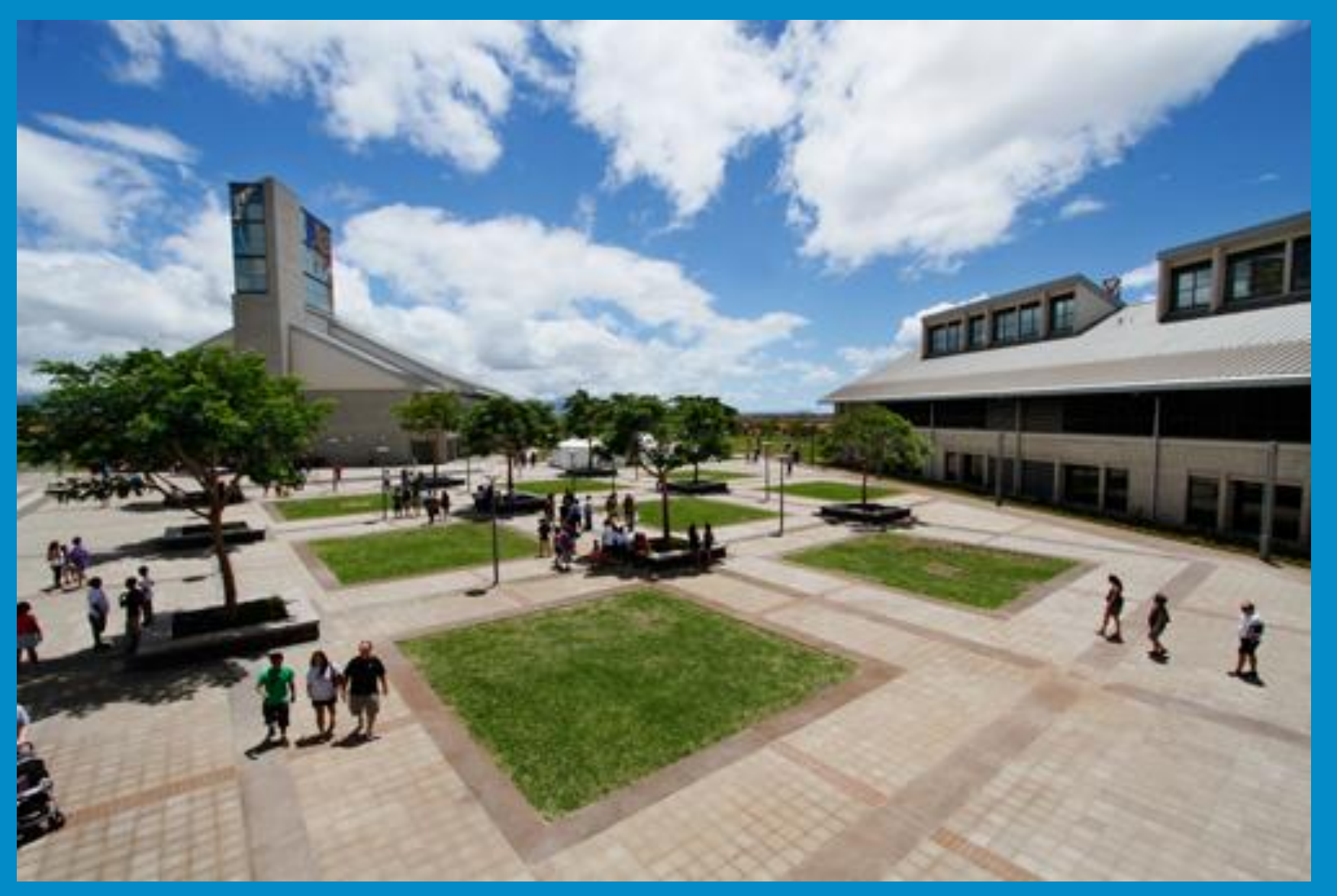




\section{Adjuncts play an important role in teaching geoscience courses}

- $13 \%$ of geoscience faculty at 4-year institutions are non-tenured or nontenure track

- Higher Percentage at 2 year colleges

- Often teach introductory courses

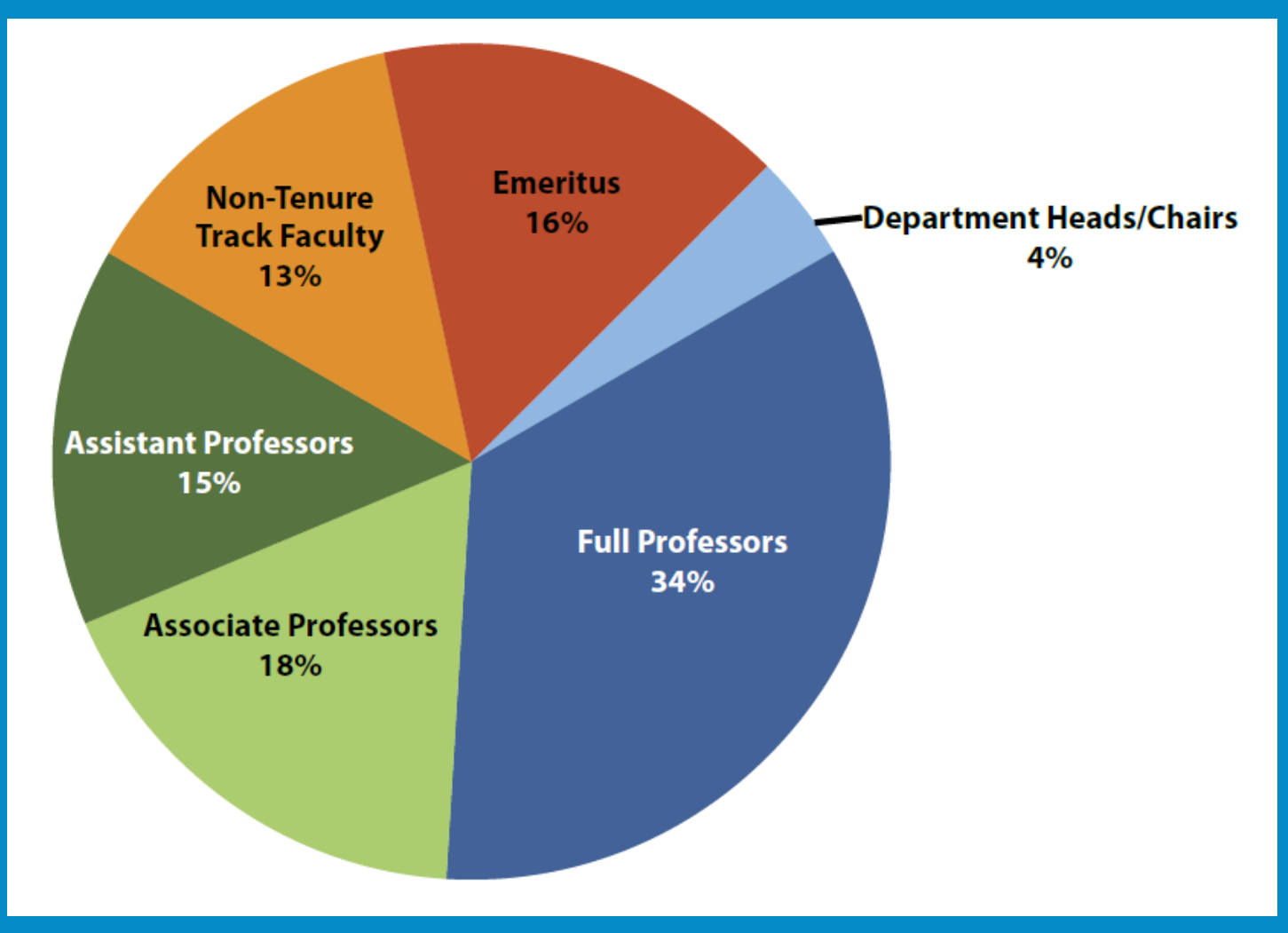

Source: Carolyn Wilson with AGI 


\section{Importance of Good Introductory Course}

Experiences

- Recruiting and retaining geology majors (Ormand, 2007)

- Increasing diversity

- Positive experiences are a major factor in choosing a geoscience major (Stokes, Levine, Flessa, 2015)

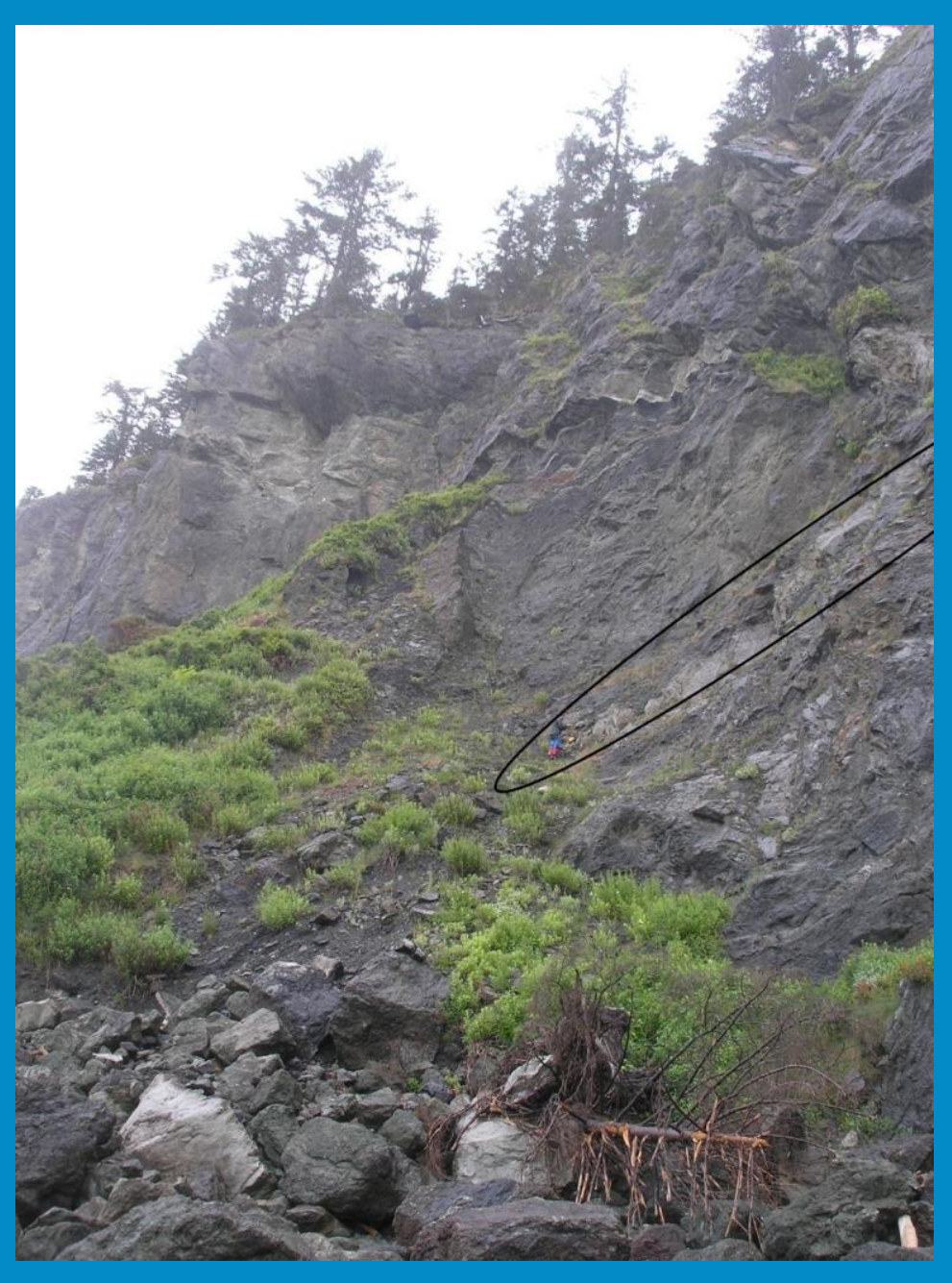




\section{Importance of Good Introductory Course Experiences}

- Goals for non-science majors:

- Scientifically literate

- Scientifically informed decisions

- Share science with others 


\section{Bad experiences create negative perceptions}

- Scared of science

- Too hard

- Difficult to understand

- "Bad at science" perception

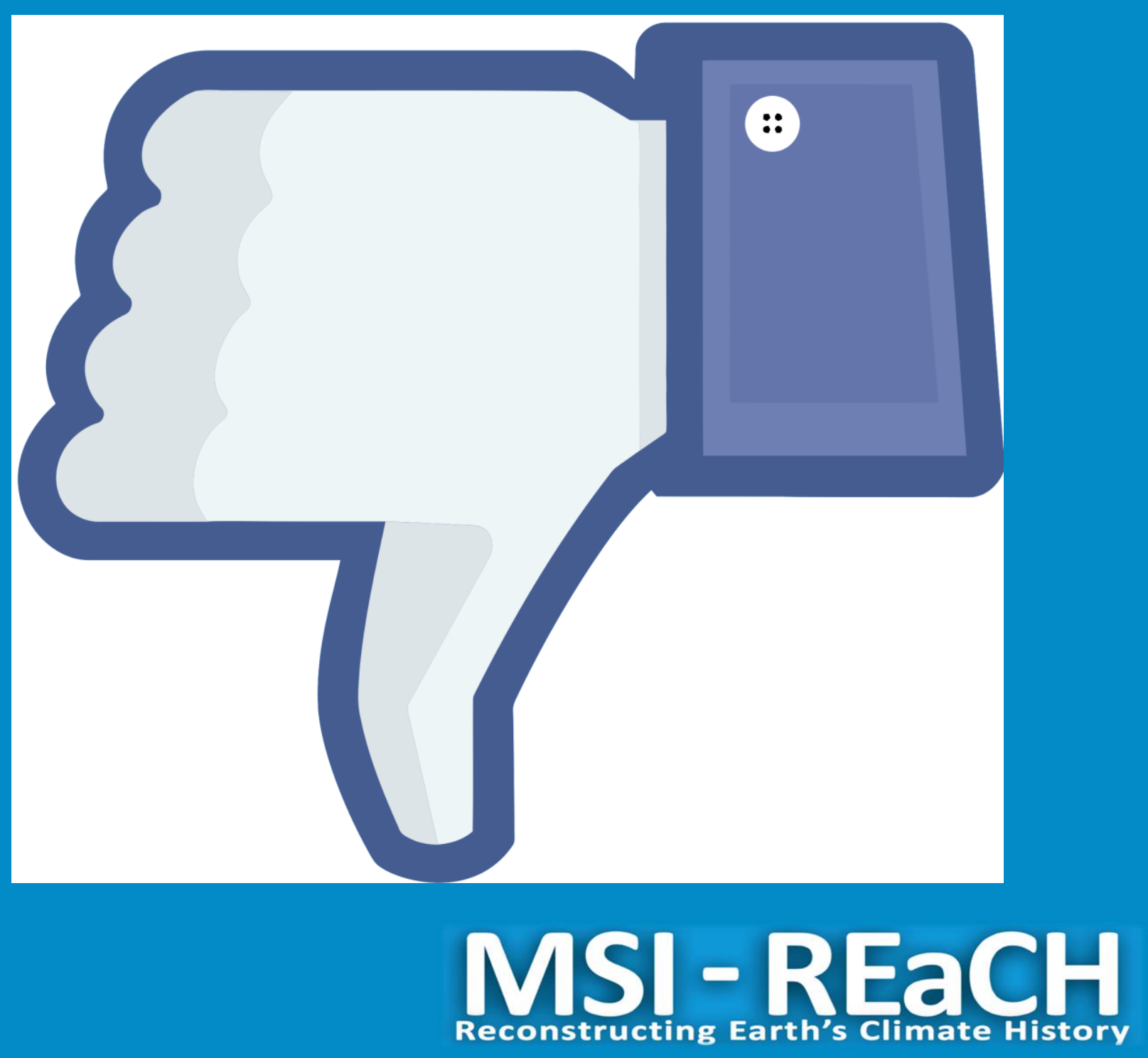




\section{Excellent teaching is important at the intro level}

\section{Utilize Your Best Faculty}

Let's face the facts: most of the students in your introductory classes aren't planning to major in geoscience. If you want to persuade them to change

their minds, you'll want to have your best teachers teach the introductory classes.

(Ormand, SERC, 2007) 


\section{The result}

- Hard to learn and implement new teaching strategies

- Teach as they have been taught: Lecture

- But: Students do better with active learning.

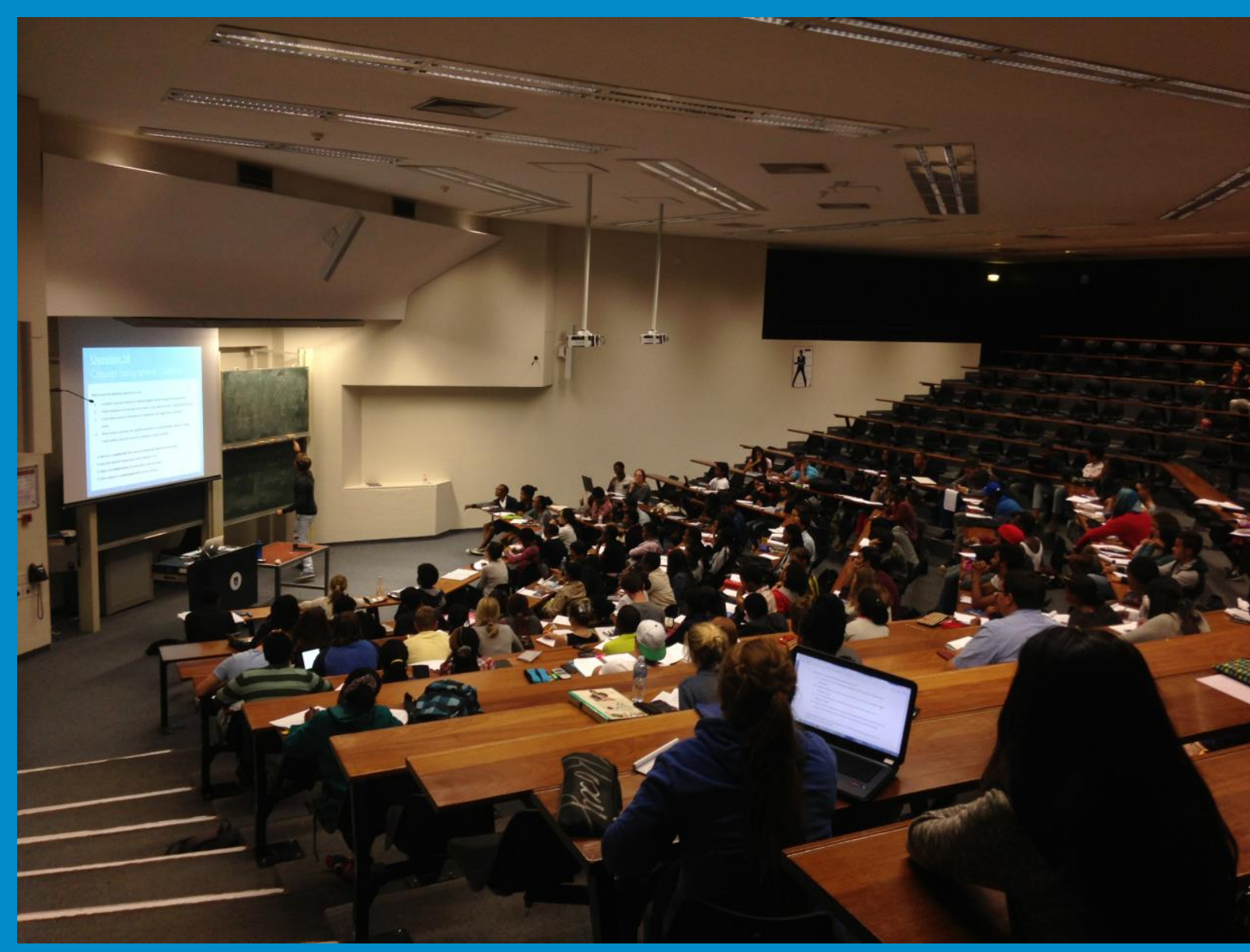




\section{How to improve adjuncts' teaching?}

- Knowledge of best teaching practices

- Keep content knowledge current

- Access to professional development (Manduca, et al 2017) 


\section{What makes professional development successful?}




\section{Adjuncts need GEMMs!}

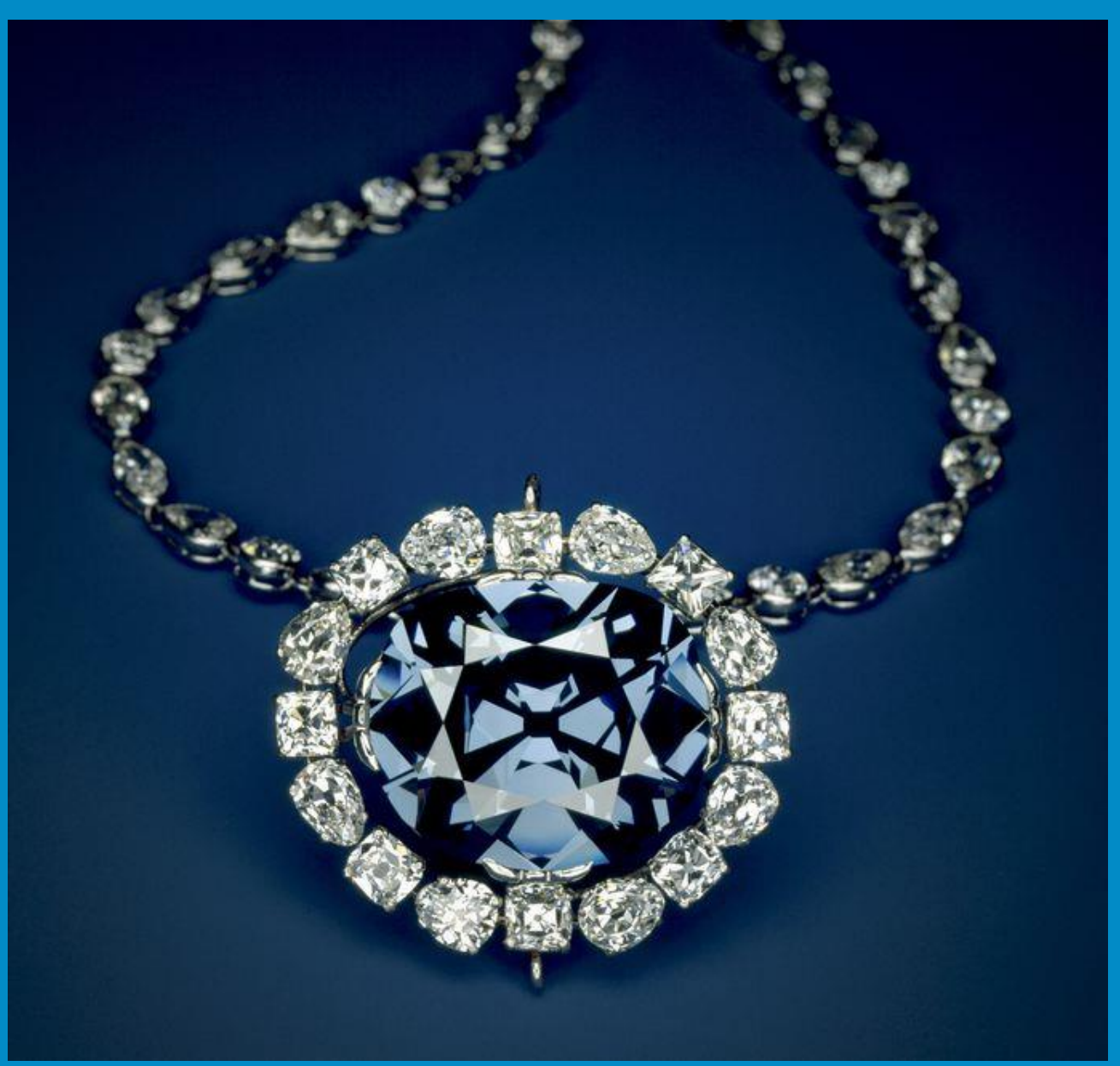




\section{Model}

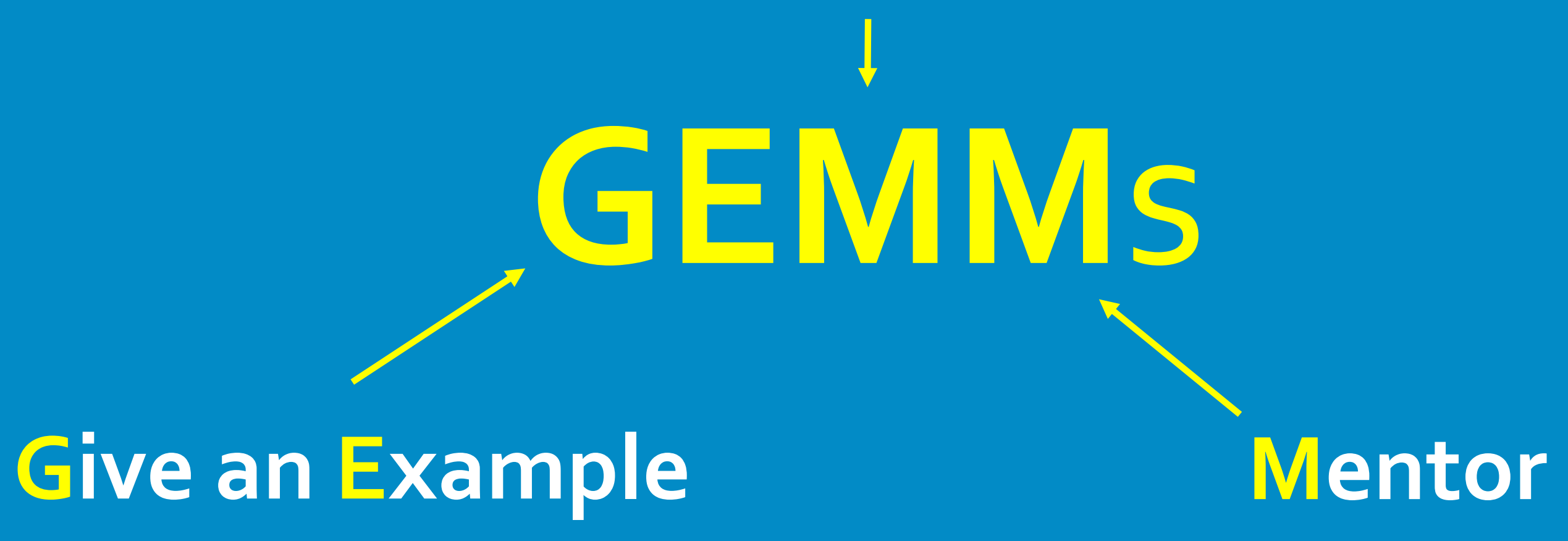

MSI-REaCH 


\section{Example of a GEMM: MSI-REaCH}

- Assist participants in teaching about climate using paleoclimate data

- For instructors at minority serving institutions
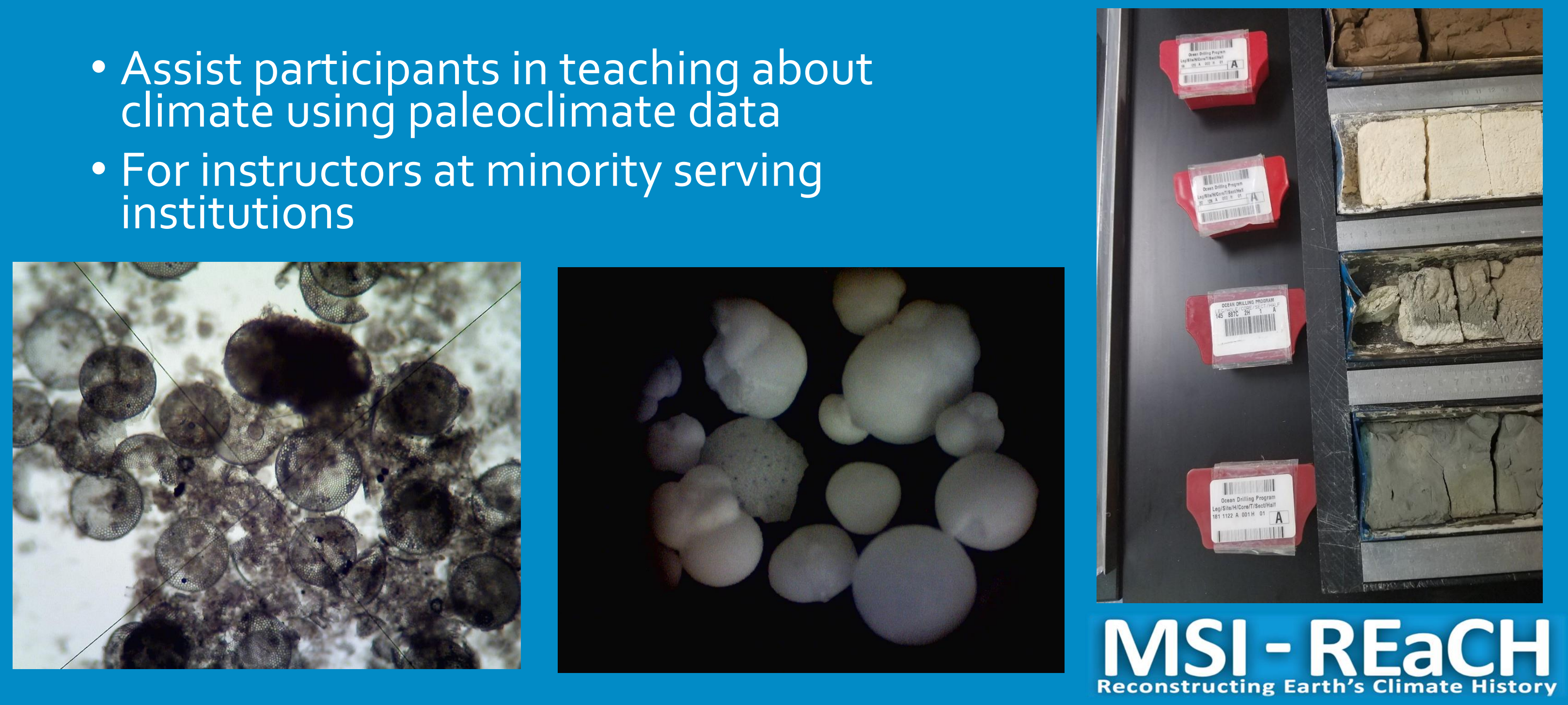


\section{Climate unit pre-MSI-REaCH}

- Climate: 1 class

- Sea level rise: 1 class

- No lab

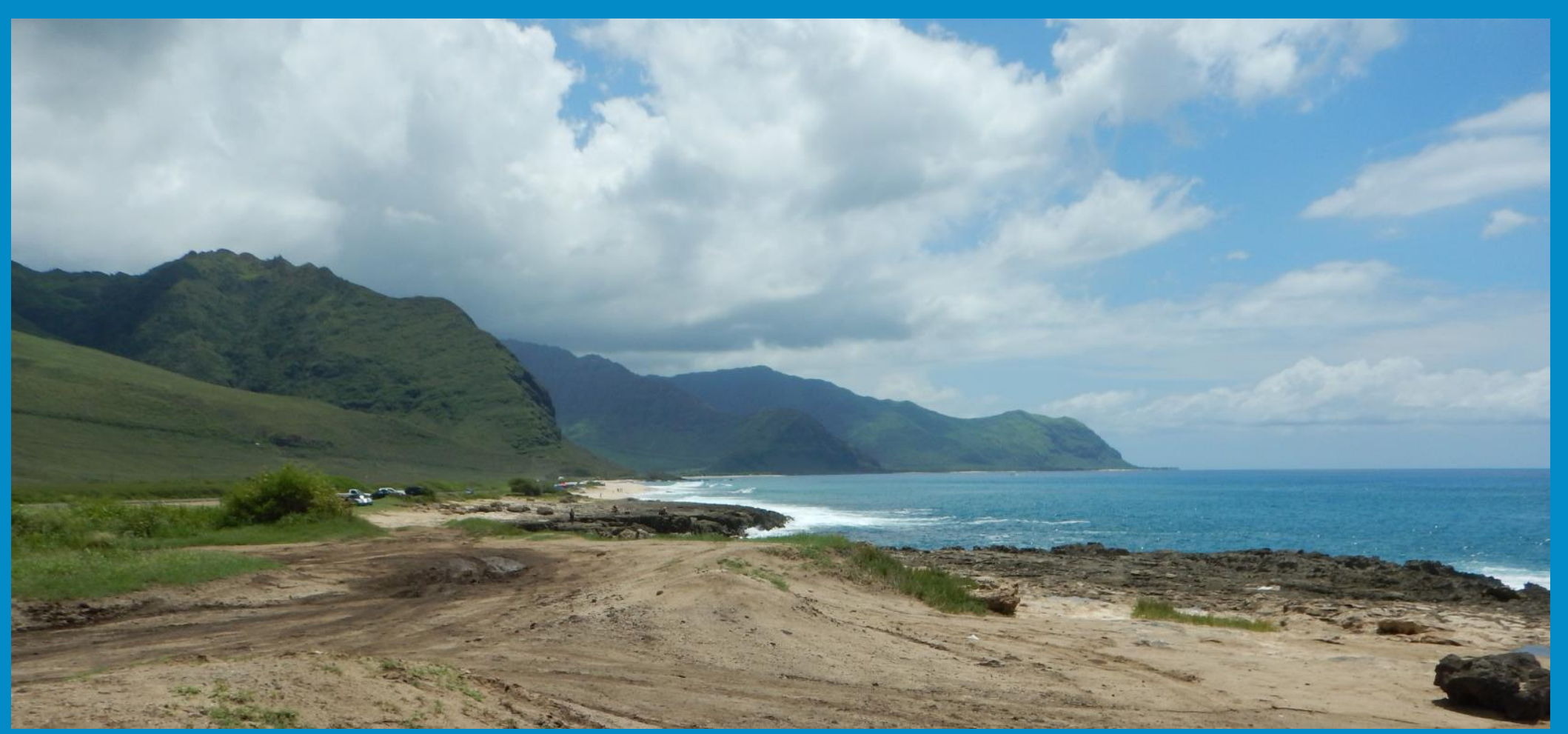




\section{How MSI-REaCH helped me: Examples of active learning}

- Laboratory manual

- Examples of exercises

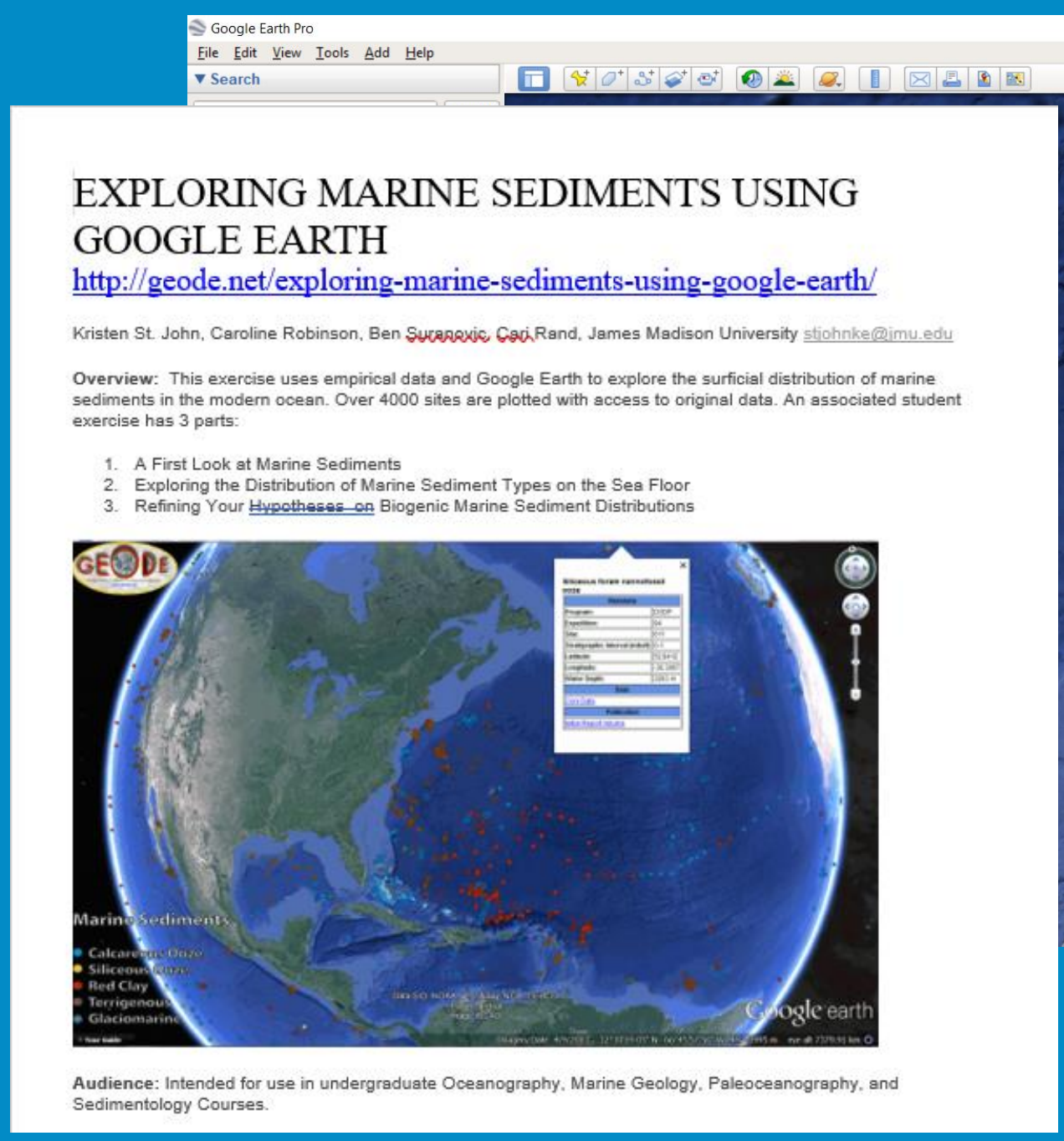

GOOGLE EARTH

http://geode.net/exploring-marine-sediments-using-google-earth/

Kristen St. John, Caroline Robinson, Ben SHrenavic GariRand, James Madison University stiohnke@imu.edu

Overview: This exercise uses empirical data and Google Earth to explore the surficial distribution of marine
sediments in the modern ocean. Over 4000 sites are plotted with access to original data. An associated student crisensas 5 partic

2. Exploring the Distribution of Marine Sediment Types on the Sea Floor
3. Refining Your Hypotheses-on Biogenic Marine Sediment Distributions

Audience: Intended for use in undergraduate Oceanography. Marine Geology. Paleoceanography, and
Sedimentology Courses

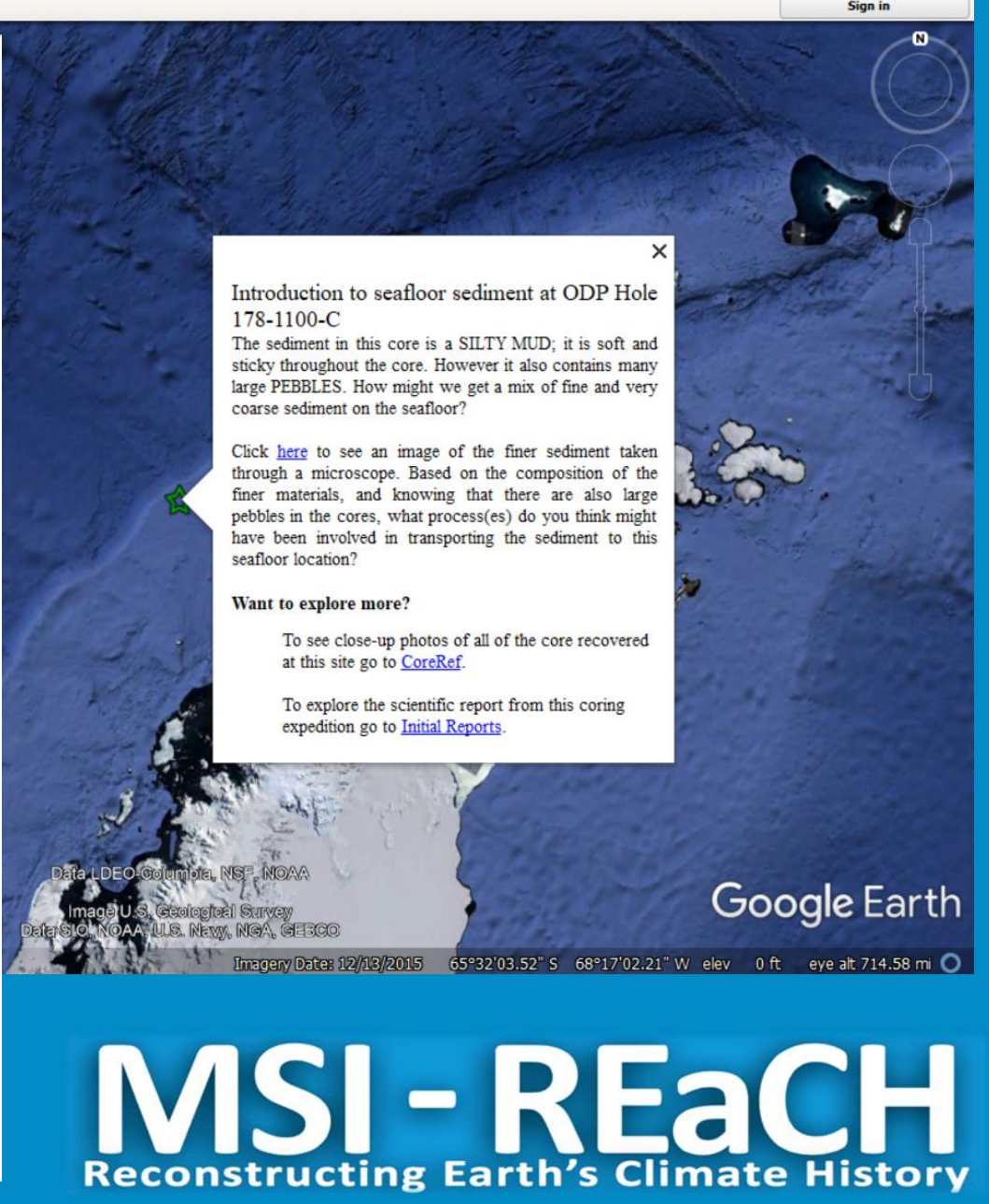


How MSI-REaCH helped me: Modeling active learning
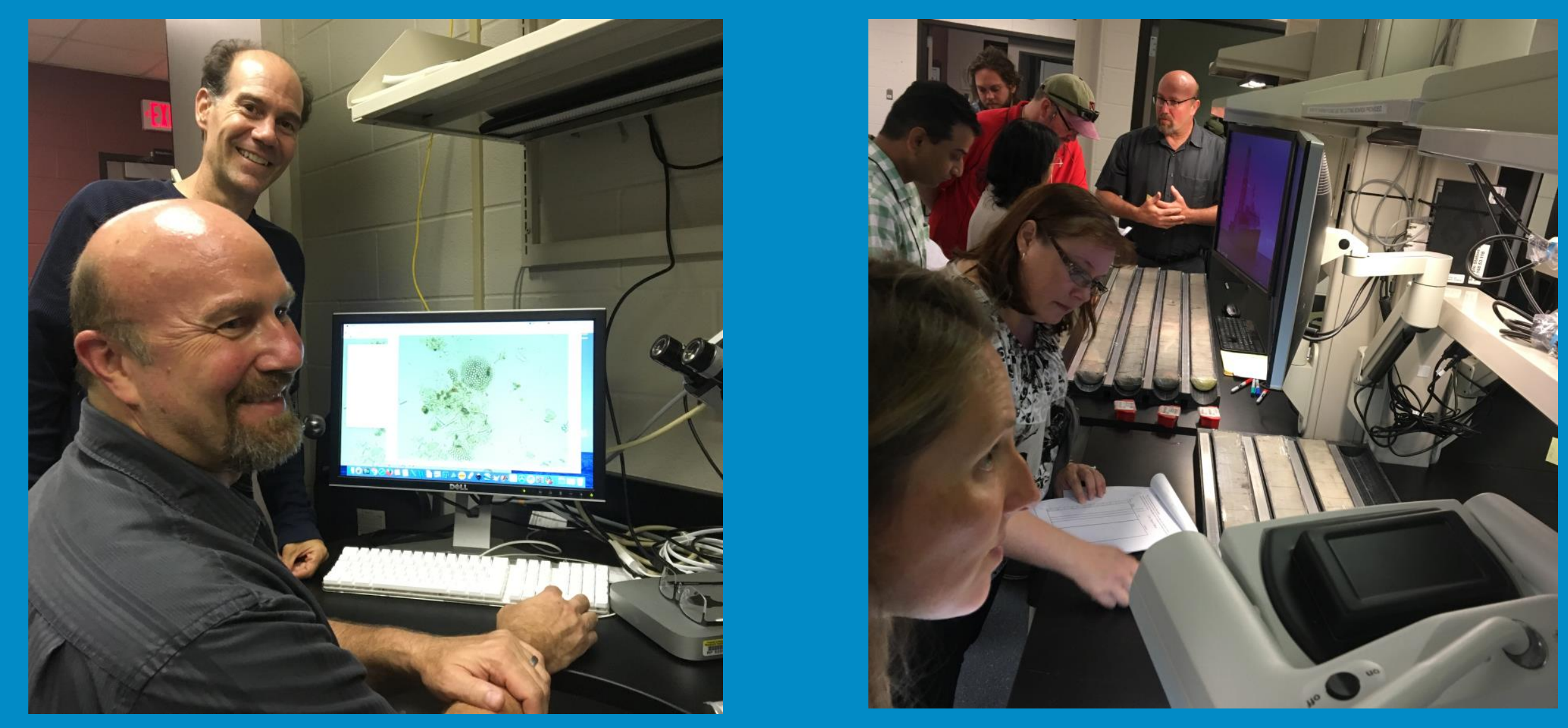

MSI-REaCH 
How MSI-REaCH helped me: Mentoring

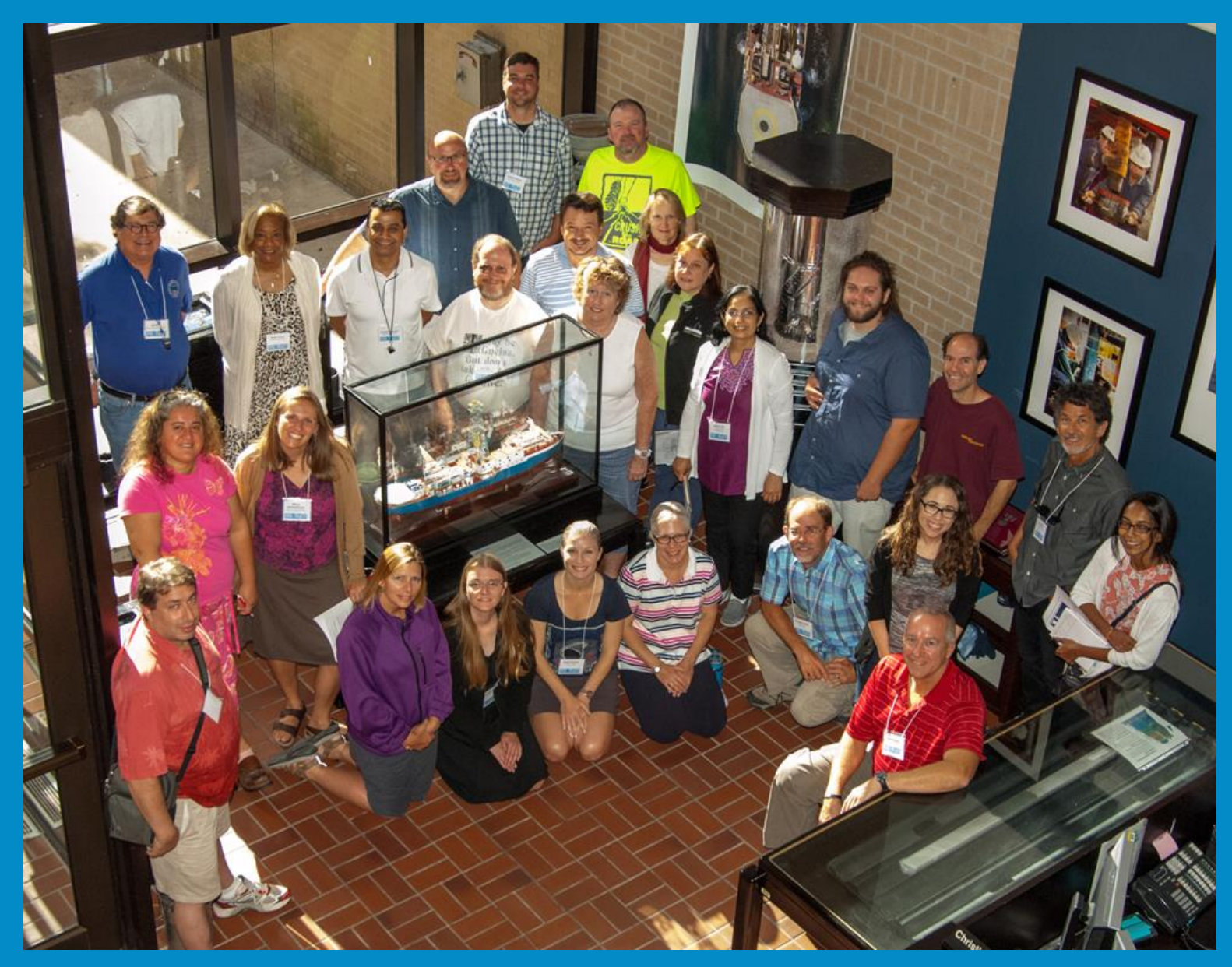




\section{MSI-REaCH results}

- Increased course content and active learning

- Lab on ocean sediment and climate

- Two interactive climate classes

- Gained confidence in teaching climate

- Students more engaged
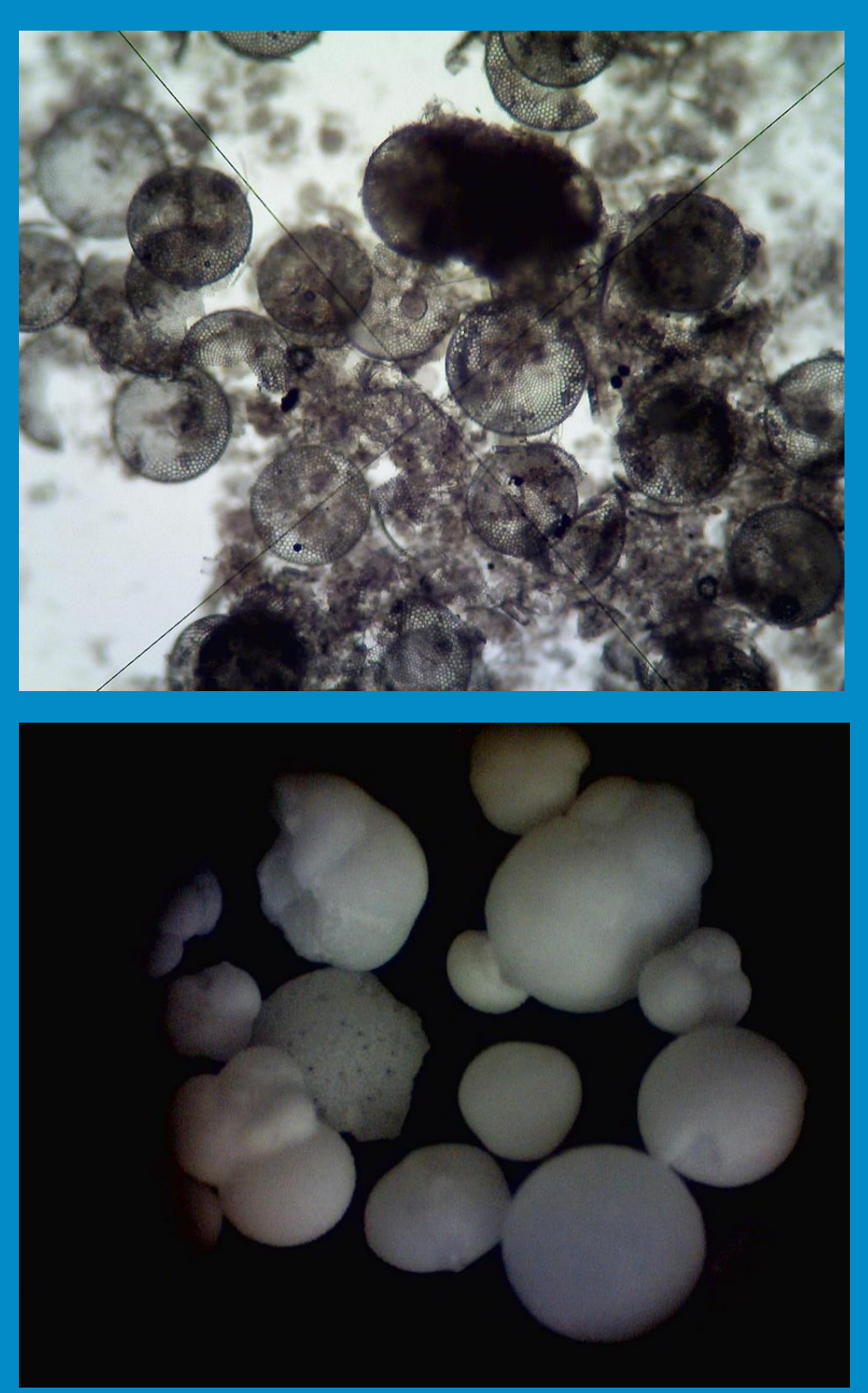


\section{Another GEMM: School of Ice}

- Planned additional class on climate

- Planned additional lab on climate
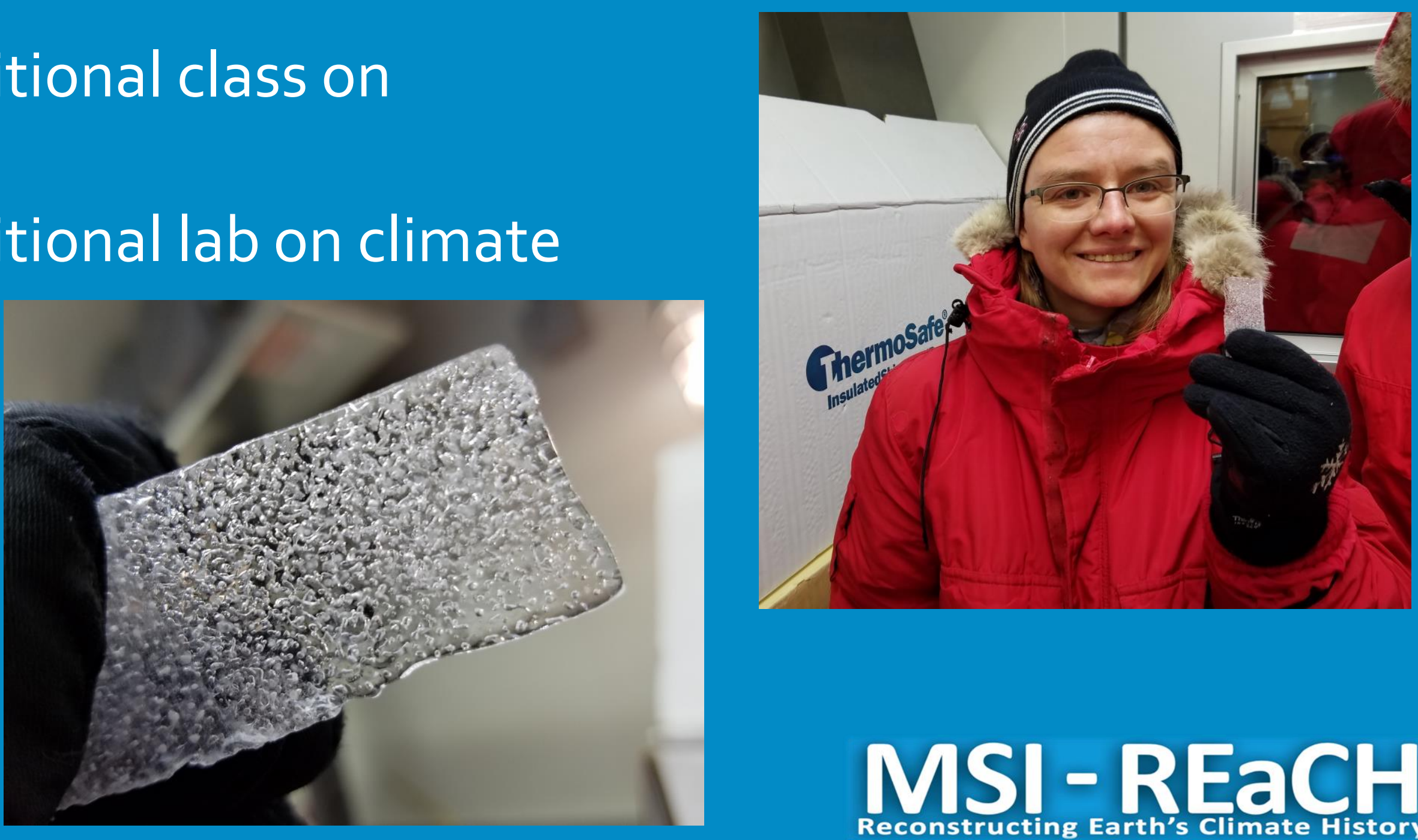


\section{Another GEMM: Climate Studies Diversity Project}

- Teach an introductory climate course

- Incorporate current climate science into other courses
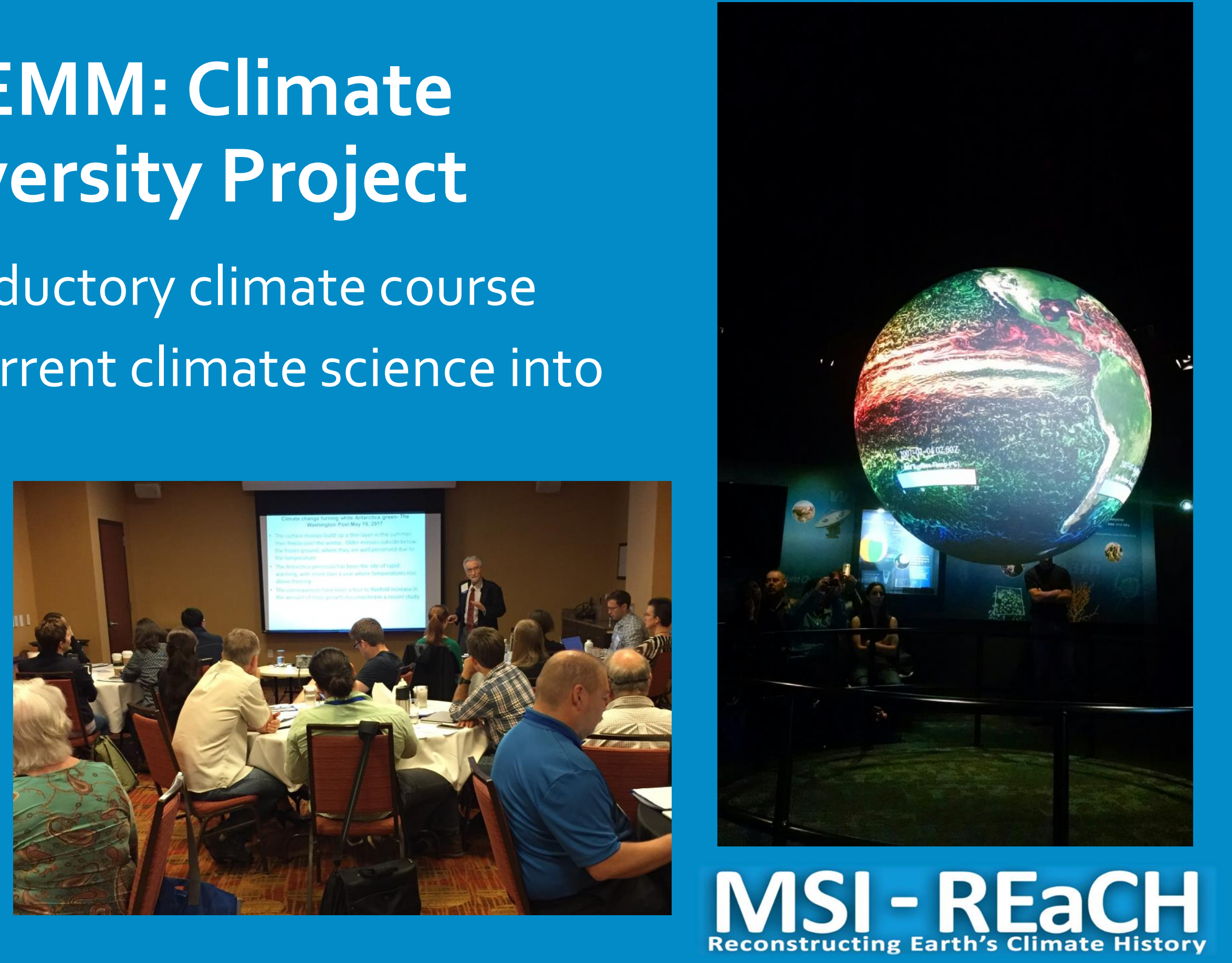


\section{How can universities help adjuncts?}

- Handbook and orientation

- Specify and model teaching expectations

- Provide examples of exemplary teaching

- Allow adjuncts to observe classes in similar disciplines

- Mentors

- Include adjuncts in professional development 


\section{What can professional societies do?}

- Yearlong mentorship program

- Reduce financial barriers

- GEMM Professional development at meetings

- Webinars

- Lists of professional development opportunities

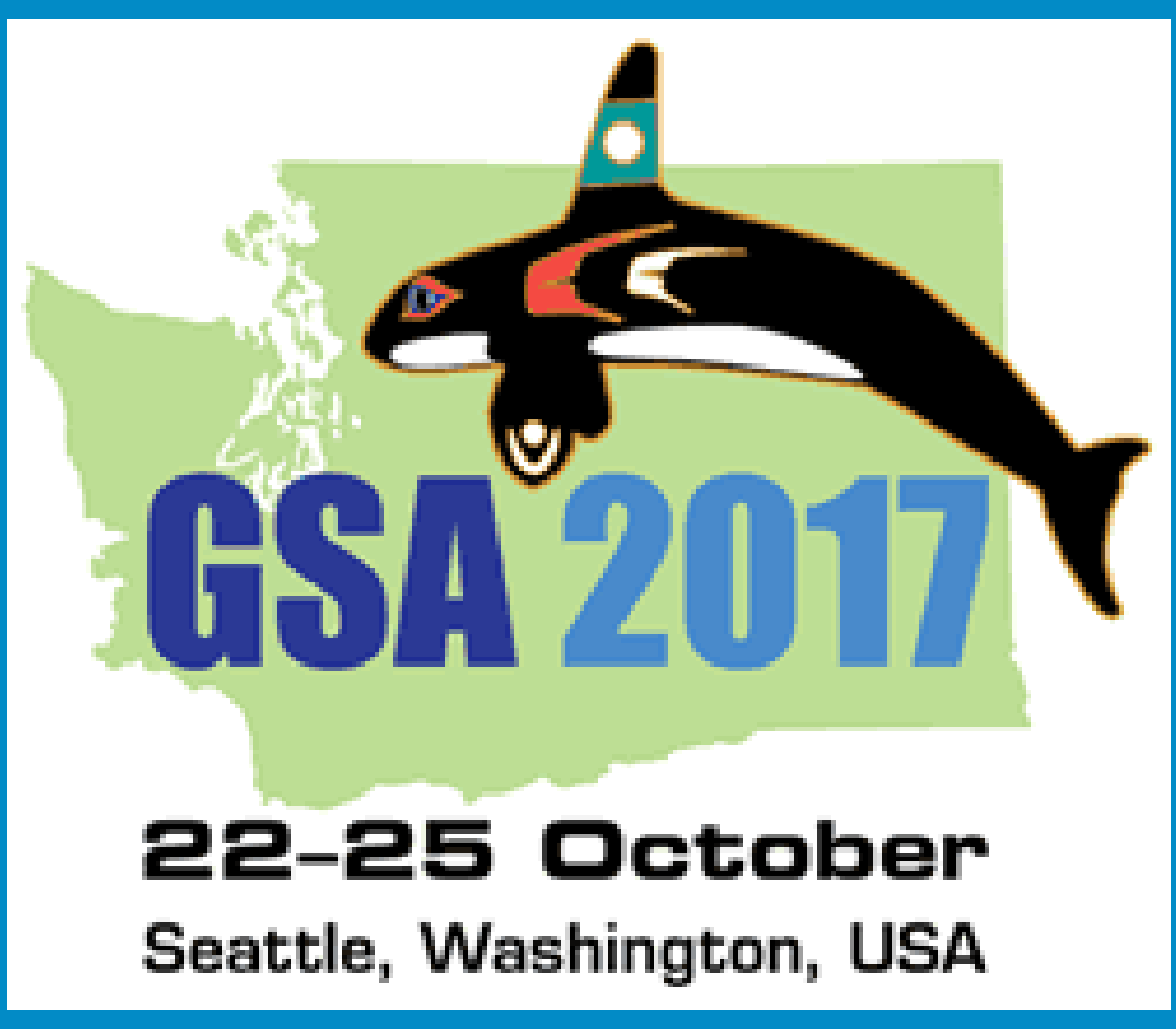




\section{Conclusions}

- Adjuncts have an important role teaching intro classes

- MSI-REaCH and other professional development programs can help adjuncts with GEMMs:

- Giving examples of exemplary teaching

- Modeling exemplary teaching

- Mentoring adjuncts as they modify their teaching strategies 


\section{Acknowledgements}

- Dr. Richard Jones, Dr. Joseph Bariyanga and the rest of the University of Hawai'i - West O'ahu Math and Science Division

- The University of Hawai'i - West O'ahu lecturer (adjunct) ' Ohana

- MSI-REaCH is funded by NSF through grant ICER-1443178 and is a collaboration between the Consortium for Ocean Leadership, the American Meteorological Society, James Madison University, Los Angeles Valley College, North Hennepin Community College, Ohio State University, Indiana University of Pennsylvania, University of Texas at El Paso, and WestEd

- The AMS Climate Studies Diversity Project is funded by NSF through Grant \# 11107968

- The School of Ice 